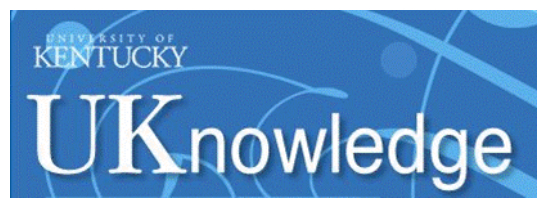

University of Kentucky

UKnowledge

\title{
Modeling and Simulation of a Utility-Scale Battery Energy Storage System
}

\author{
Oluwaseun M. Akeyo \\ University of Kentucky, ochichikeyo@gmail.com \\ Vandana Rallabandi \\ University of Kentucky, vandana.rallabandi@uky.edu \\ Nicholas Jewell \\ LG\&E and $K U$
}

Dan M. Ionel

University of Kentucky, dan.ionel@uky.edu

Follow this and additional works at: https://uknowledge.uky.edu/peik_facpub

Part of the Power and Energy Commons

Right click to open a feedback form in a new tab to let us know how this document benefits you.

\section{Repository Citation}

Akeyo, Oluwaseun M.; Rallabandi, Vandana; Jewell, Nicholas; and Ionel, Dan M., "Modeling and Simulation of a Utility-Scale Battery Energy Storage System" (2019). Power and Energy Institute of Kentucky Faculty Publications. 16.

https://uknowledge.uky.edu/peik_facpub/16

This Conference Proceeding is brought to you for free and open access by the Power and Energy Institute of Kentucky at UKnowledge. It has been accepted for inclusion in Power and Energy Institute of Kentucky Faculty Publications by an authorized administrator of UKnowledge. For more information, please contact UKnowledge@lsv.uky.edu. 


\title{
Modeling and Simulation of a Utility-Scale Battery Energy Storage System
}

\author{
Digital Object Identifier (DOI) \\ https://doi.org/10.1109/PESGM40551.2019.8974042
}

\section{Notes/Citation Information}

Published in 2019 IEEE Power \& Energy Society General Meeting (PESGM).

(c) 2019 IEEE Copyright Notice. "Personal use of this material is permitted. Permission from IEEE must be obtained for all other uses, in any current or future media, including reprinting/republishing this material for advertising or promotional purposes, creating new collective works, for resale or redistribution to servers or lists, or reuse of any copyrighted component of this work in other works."

The document available for download is the authors' manuscript version that is accepted for publication. The final published version is copyrighted by IEEE and will be available as: O. Akeyo, V. Rallabandi, N. Jewell and D.M. Ionel, "Modeling and Simulation of a Utility-Scale Battery Energy Storage System," 2019 IEEE Power \& Energy Society General Meeting (PESGM), Atlanta, GA, 2019, 6p. 


\title{
Modeling and Simulation of a Utility-Scale Battery Energy Storage System
}

\author{
Oluwaseun Akeyo ${ }^{1}$, Vandana Rallabandi ${ }^{1}$, Nicholas Jewell ${ }^{2}$, and Dan M. Ionel ${ }^{1}$ \\ ${ }^{1}$ SPARK Laboratory, ECE Department, University of Kentucky, Lexington, KY \\ om.akeyo@ieee.org, vandana.rallabandi@ieee.org, dan.ionel@ieee.org \\ ${ }^{2} \mathrm{LG} \& \mathrm{E}$ and KU, Louisville, KY \\ Nicholas.Jewell@lge-ku.com
}

\begin{abstract}
This paper presents the modeling and simulation study of a utility-scale MW level Li-ion based battery energy storage system (BESS). A runtime equivalent circuit model, including the terminal voltage variation as a function of the state of charge and current, connected to a bidirectional power conversion system (PCS), was developed based on measurements from an operational utility-scale battery demonstrator. The accelerated response of the battery unit was verified by pulse discharging it from maximum to minimum SOC and its application for grid resiliency was demonstrated through an example droop control frequency response. For the purpose of validating the equivalent BESS model, experimental results retrieved from the LG\&E and KU E.W. Brown solar facility, which houses a 1MW/2MWh operational BESS and a 1MVA variable load bank were compared with simulation results from an equivalent model developed in PSCAD/EMTDC software, which is a tool typically employed for transient analysis.
\end{abstract}

Index Terms-BESS, battery, energy storage, grid connected converter, battery modeling, Li-ion battery, performance testing, parameter estimation, PSCAD.

\section{INTRODUCTION}

The adoption of a distributed energy generation system and the integration of intermittent power sources such as wind and solar poses multiple threats to the stability of the power grid [1]. Energy storage systems provide a viable means of grid integration for these renewable sources, and in addition, also can perform a number of ancillary services, which are beneficial to utility companies, as well as customers, leading potentially to investment savings. Some of these functions include improving the power delivery quality, frequency regulation and reactive power support.

The focus of many research works concerning battery energy storage system (BESS) models has mostly been on the cell level characterization [2]-[4] or related to the control of the power electronics converter which interconnects it with the utility grid or the load [5]-[7]. With the increased grid integration of large BESS, and the demand for safe and efficient ways to utilize it, emphases should be placed on the modeling of the actual battery system, which includes multiple cells connected in series and parallel. A battery model capable of effectively predicting the runtime and voltagecurrent behavior can be used for scheduling the operation such that as far as possible, the distributed and intermittent power generation are matched with the load demand, as well as for the development of controls to ensure optimal usage and safe operation.

As opposed to conventional approaches, where the cells constituting the battery are represented by fixed electrical components such as capacitors and resistances, described for example in [8], the proposed work employs a mathematical equivalent battery bank model over an accelerated time scale, with the values of the electrical components varying as a function of the state of charge (SOC). The model is developed for a utility-scale 1MW/2MWh BESS, using experimental data retrieved from the LG\&E and KU E.W. Brown solar facility.

In order to verify the battery bank model, it was pulse discharged from maximum to minimum SOC on an accelerated time scale, and its voltage variation was compared with experimental measurements performed under the same conditions. In addition, the operation of the BESS while performing ancillary services for the grid was demonstrated through simulations and measurements for an autonomous frequency response control. The system simulations were performed using PSCAD/EMTDC an electromagnetic timedomain simulation environment and study tool.

\section{BESS EXPERIMENTAL SETUP AND TESTS}

The 1MW/2MWh experimental BESS setup at the LG\&E and KU E. W. Brown universal solar facility includes a Liion battery bank stored in two $6.06 \times 2.44 \times 2.6 \mathrm{~m}$ shipping containers. Each container has ten racks, and there are seventeen modules per rack. Each of these LG Chem M48126P3b1 ESS battery modules has a nominal output voltage of $51.8 \mathrm{~V}$ at $126 \mathrm{Ah}$, and is made up of 14 cells. These modules are connected in series and parallel so that the terminal voltage from each container is about $950 \mathrm{Vdc}$ fed as input to the Dynapower CPS-1000 1MW power conversion system (PCS). The bidirectional PCS is interfaced with the grid via a $480 \mathrm{~V} / 13.2 \mathrm{kV}$ transformer. For tests conducted in the islanded mode, the BESS may be connected to an on-site 1MVA simplex load load (fig.1)

The experimental tests involve operating the BESS with multiple charge/discharge cycles in order to obtain its equivalent circuit parameters. As opposed to conventional approaches, where the battery cell is pulse discharged at constant current, the setup PCS is reference power controlled. Therefore, it was pulse discharged at its rated power and its terminal 


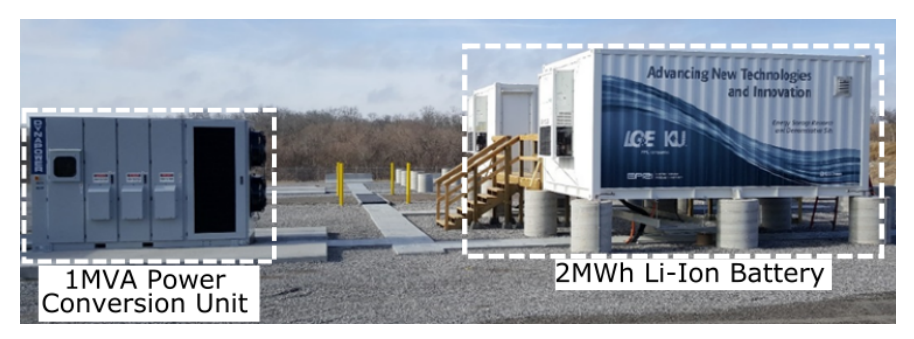

(a)

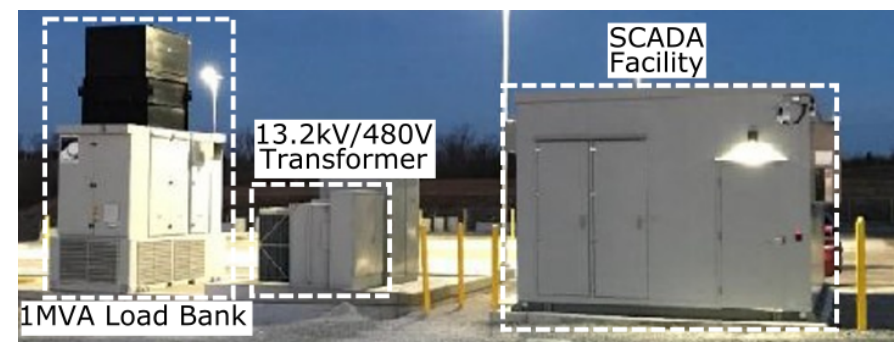

(b)

Figure 1. The $1 \mathrm{MW} / 2 \mathrm{MWh}$ battery energy storage system (BESS) setup at the E.W. Brown LG\&E and KU facility showing: the 1MVA bidirectional power conversion unit used to interconnect the $2 \mathrm{MWh} \mathrm{Li}$-ion battery to the grid (a), and the programmable load bank, which may be connected to the high voltage side of the step-up transformer when the BESS is operated in islanded mode while the SCADA facility provides high resolution data management and system control (b).

voltage response was analyzed, in order to estimate the battery parameters corresponding to the combination of all cells.

\section{BATTERY BANK MODEL IN PSCAD/EMTDC}

A battery cell is generally modeled as a controllable voltage source connected in series with a variable resistor and multiple RC branches (Fig. 2).

The characteristics of a battery vary with its chemical and physical parameters such as temperature, state of charge (SOC), state of health and the number of cycles. For simplicity, only the variation due to the battery SOC is being considered in this approach. The battery SOC may be represented as:

$$
\gamma(\%)=\gamma_{i}(\%)-\frac{100}{C_{A h} \cdot 3600} \int_{0}^{t} i_{b} d t
$$

where $\gamma$ and $\gamma_{i}$ represents the percentage final and initial battery SOC, respectively; $C_{A h}$, the battery rated capacity in Ampere-hour; $i_{b}$, battery output current and $t$ is the time. $C_{A h}$ is multiplied by 3600 in order to convert it to Ampere-second. The terminal voltage of the battery bank may be represented as:

$$
v_{b}(t)=v_{o c}-i_{b}(t) R_{0}-v_{R C 1}(t)-v_{R C 2}(t),
$$

and the RC branch voltages, $v_{R C 1}(t)$ and $v_{R C 2}(t)$ may be found from their first derivatives, $v_{R C 1}^{\dot{R}}(t)$ and $v_{R C 2}(t)$ from the following,

$$
v_{R C n}(t)=\frac{1}{C_{n}}\left(i_{b}(t)-\frac{v_{R C n}(t)}{R_{n}}\right), \quad \text { for } \mathrm{n}=1 \text { and } 2 \text {, }
$$

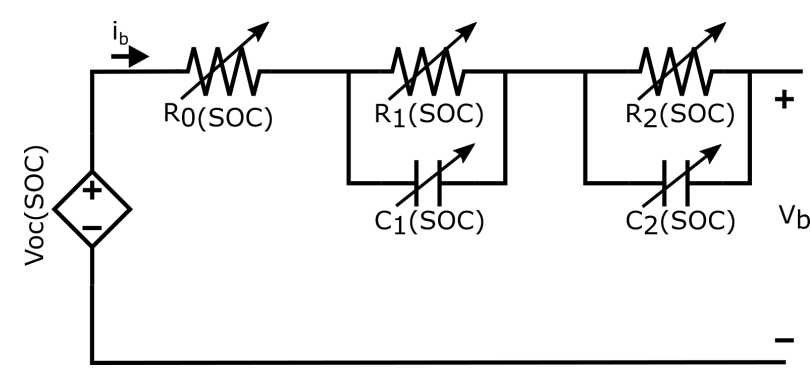

Figure 2. An equivalent circuit diagram for a single battery cell. In this approach, for simplicity, parameters such as cell temperature, number of charge and discharge cycles, self-discharge and cell state of health are neglected.

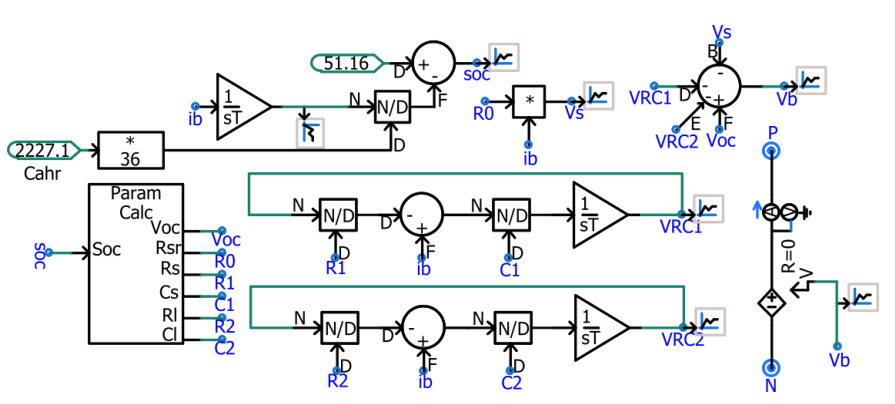

Figure 3. The developed runtime equivalent circuit for a utility-scale $1 \mathrm{MW} / 2 \mathrm{MWh}$ battery bank in PSCAD/EMTDC software.

where $v_{b}$ represents the battery terminal voltage; $V_{o c}$, the battery open-circuit voltage; $R_{0}$, the series resistance, and $R_{n}$ and $C_{n}$, the resistances and capacitances for the $n^{t h}$ battery $\mathrm{RC}$ branch.

An equivalent battery bank model was developed in PSCAD/EMTDC based on (1)-(3). This model mathematically calculates the voltage across $R_{0}$ and the RC branches, which is then subtracted from the open-circuit voltage to obtain the battery terminal voltage. The terminal voltage is used to regulate a controllable dc source, in order to model the voltage response of the battery and capture its dynamic behavior (Fig. 3). The estimated single-variable functions for each of the battery equivalent circuit parameters were thus retrieved from the experimental test and described as:

$$
\begin{gathered}
v_{o c}(\gamma)=10.16 \cdot \exp ^{-3.389 \cdot \gamma} 0.002081 \cdot \gamma^{3} \\
-0.02149 \cdot \gamma^{2}+1.918 \cdot \gamma+814.5 \\
R_{0}(\gamma)=0.00584 \cdot \exp ^{-0.088 \cdot \gamma}+0.00558 \\
R_{1}(\gamma)=30.9068 \cdot \exp ^{-1.72223 \cdot \gamma}+0.003434 \\
C_{1}(\gamma)=8.66 \times 10^{7} \cdot \exp ^{-0.2416 \cdot \gamma}+1.007 \times 10^{6} \\
R_{2}(\gamma)=-4.23731 \cdot \exp ^{-1.4753 \cdot \gamma}+0.0015 \\
C_{2}(\gamma)=-6.68 \times 10^{5} \cdot \exp ^{-0.8311 \cdot \gamma}+30379
\end{gathered}
$$

The Param Calc block in Fig. 3 is used to calculate the open-circuit voltage, resistor and capacitor values of the battery bank as a function of the SOC. This subsystem is modeled in PSCAD/EMTDC environment using arithmetic 


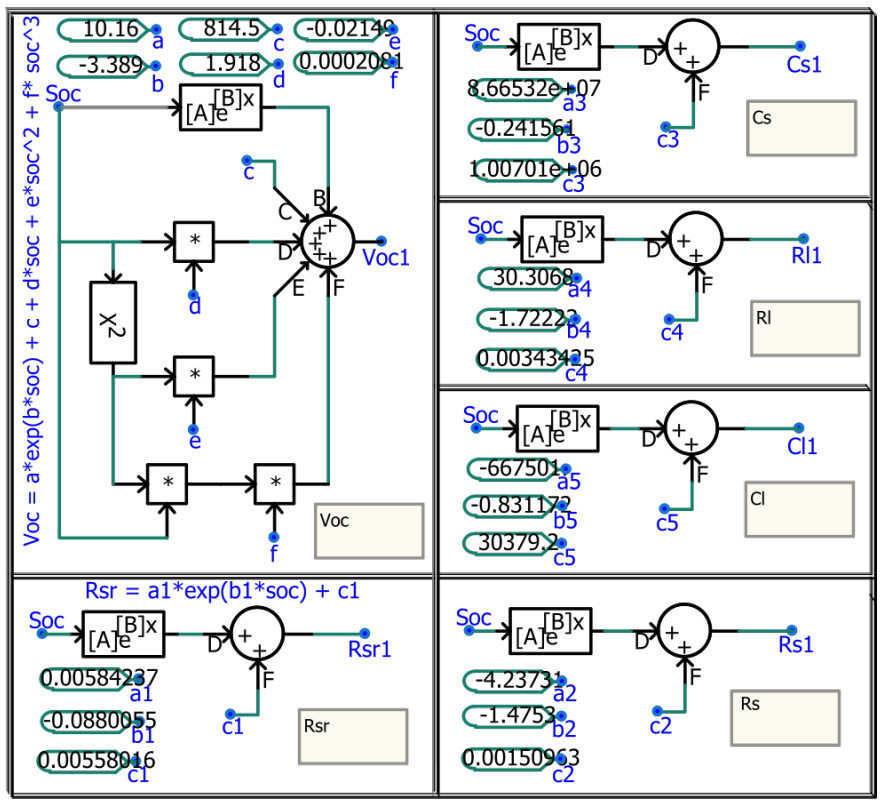

Figure 4. The estimation of equivalent circuit parameters in the PSCAD/EMTDC software. Best fit models relating the electric equivalent circuit parameters to the battery SOC were derived from experimental measurements on the LG\&E and KU battery.

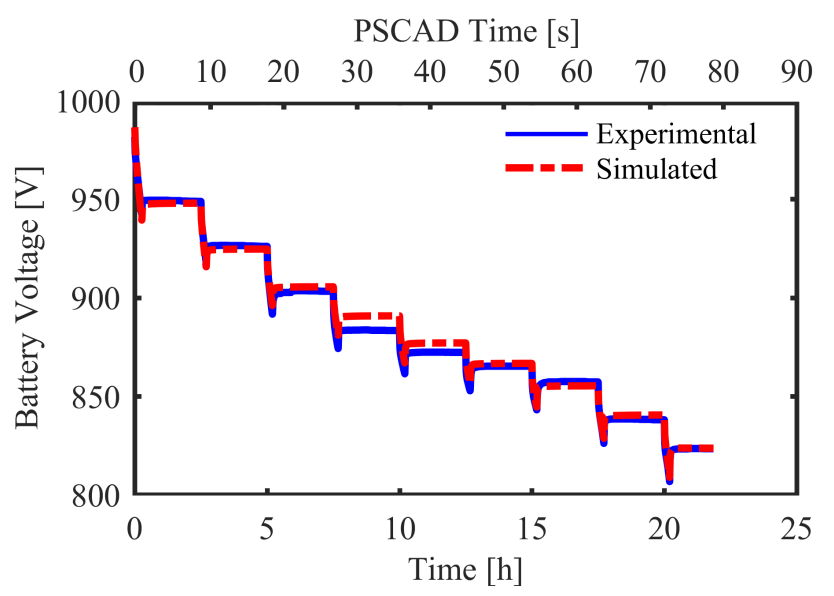

Figure 5. The battery terminal voltage variation during pulse discharge.

blocks that describes the mathematical relations presented in (4)-(9) (Fig 4).

In order to verify the proposed model, it was tested under the same conditions as the experimental measurements. The model is fed from a current source, whose output is identical to the measured dc current of the experimental unit. For the purpose of reducing the simulation time, the battery model was simulated on an accelerated time scale, $\alpha$. Hence, the RC branch voltage expressions in (3) may be rewritten as:

$v_{R C n}(\alpha)=\frac{1}{K C_{n}} \int\left(i_{b}(\alpha)-\frac{v_{R C n}(\alpha)}{R_{n}}\right) \cdot d \alpha$, for $\mathrm{n}=1$ and 2 ,

where $\alpha=K t$, is the accelerated time, which is a multiple of

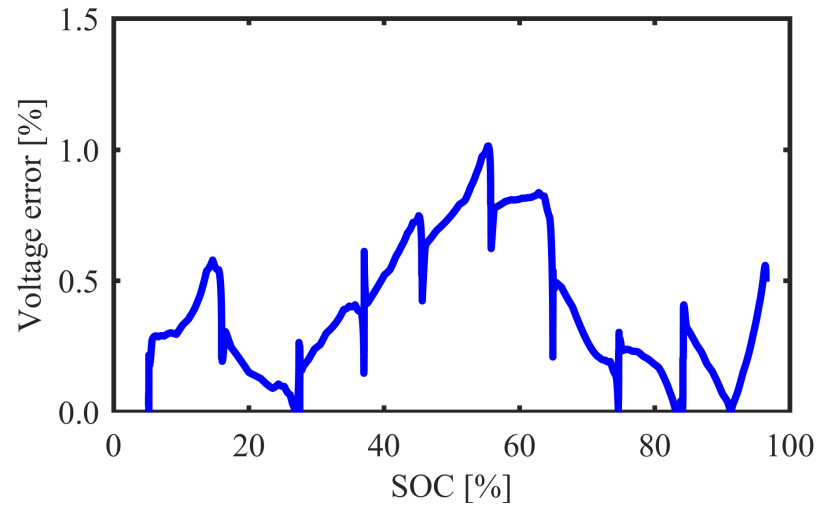

Figure 6. The variation of percentage error between the estimated and measured battery terminal voltages with the SOC. Based on the defined parameters, up to $99 \%$ accuracy in the estimated voltage is achievable.

the experimental time. For this approach, $K$ was selected to be equal to 0.001 . Also, (1) and (2) may be rewritten in terms of $\alpha$. The terminal voltage of the equivalent battery bank model in PSCAD/EMTDC was compared with the experimental result for a pulse discharge of the battery from the maximum to minimum SOC, and an agreement between the results was established (Fig. 5). The developed battery bank model demonstrated an accuracy up to $99 \%$, with the maximum error occurring around 50\% SOC (Fig. 6).

\section{Power Electronics Control}

The BESS, represented in PSCAD/EMTDC by the proposed equivalent circuit model, is connected to the grid, in this case, a 3-phase $13.2 \mathrm{kV}$ voltage source, through a two level bidirectional inverter, and a $480 \mathrm{~V} / 13.2 \mathrm{kV}$ transformer. (Fig. 7). For this inverter, a decoupled scheme identical to [5], which allows the independent control of real and reactive powers is employed (Fig. 8). The $d q-$ rotating reference frame is aligned with the grid voltage using the transformation angle, $\phi$, obtained from a phase locked loop. The inverter active $\left(P_{r e f}^{*}\right)$ and reactive $\left(Q_{r e f}^{*}\right)$ power references, may be set at the desired values, depending upon the operating mode, for example, frequency regulation, power smoothing and voltage compensation. These are used find the $d q-$ current commands using the following,

$$
i_{d}^{*}=\frac{2}{3} \frac{P_{r e f}^{*}}{v_{d}}, \quad i_{q}^{*}=\frac{2}{3} \frac{Q_{r e f}^{*}}{v_{q}},
$$

where $v_{d}, v_{q}$ and $i_{d}^{*}, i_{q}^{*}$, are d-q reference frame voltage and currents, respectively. In the case of the frequency response operation studied here, the reference active power is derived from the frequency variation, while the reactive power reference is maintained at zero.

\section{Autonomous Frequency Response}

In the conventional grid dominated by synchronous generators, an imbalance between the generation and demand 


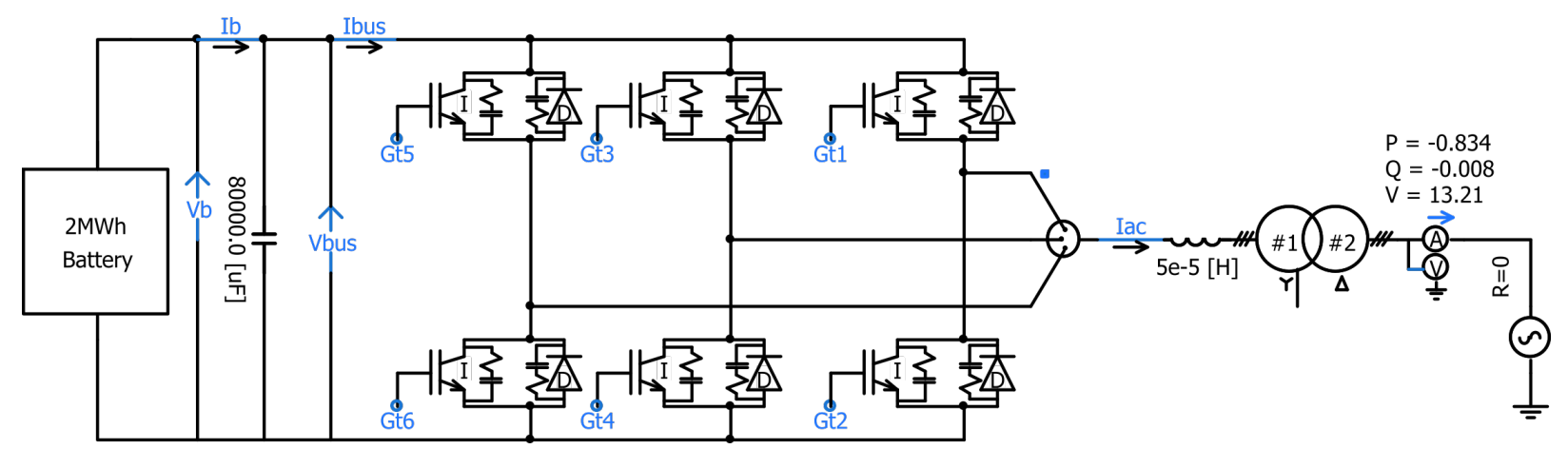

Figure 7. Schematic representation of battery energy storage system in PSCAD/EMTDC software. The system includes a 1MW/2MWh battery bank connected to the grid through a bidirectional power conditioning system and a 1MVA transformer.

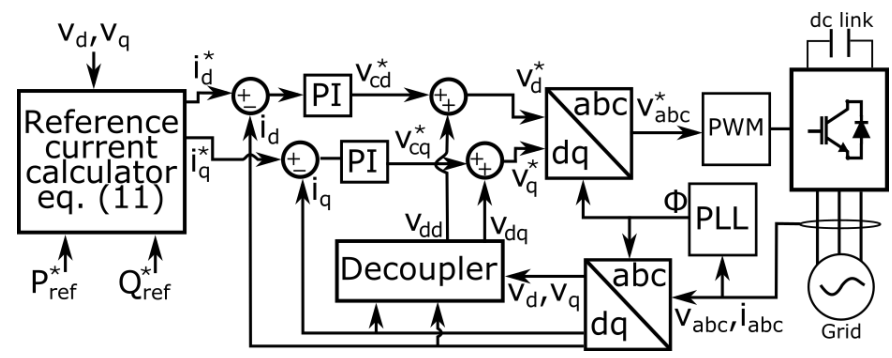

Figure 8. An example inverter control scheme, allowing independent control over the active and reactive power. $\mathrm{P}_{r e f}^{*}$ and $\mathrm{Q}_{r e f}^{*}$ represent the real and reactive reference powers, respectively.

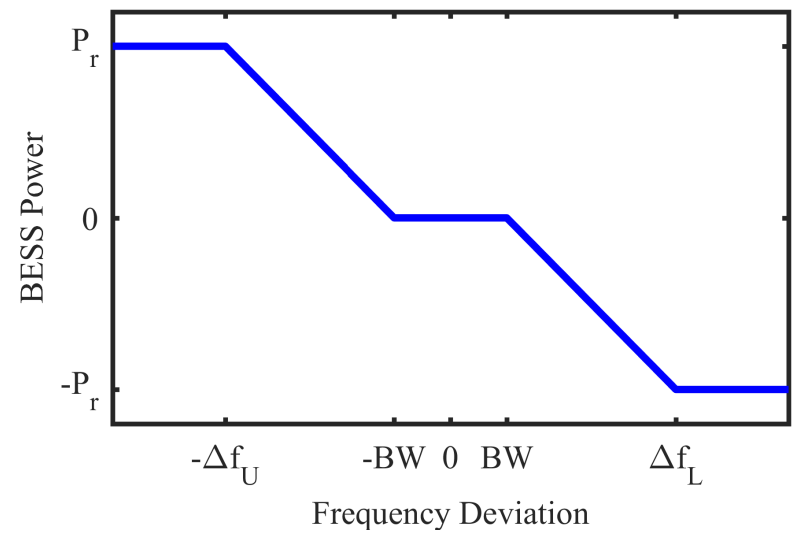

Figure 9. An example BESS droop characteristic for frequency response. The BESS is inactive when the frequency deviation is within the dead-band $( \pm$ BW) and charges or discharges at rated power, $P_{r}$ at frequencies exceeding the lower and upper frequency deviation control bounds $\left(\Delta f_{L}\right.$ and $\left.\Delta f_{U}\right)$, respectively.

may lead to deviation in the system frequency. The grid frequency tends to increase when the generation is in surplus, and falls when the load exceeds the generation. In this regard, typically, utilities install additional high-ramping generators in the form of spinning reserves which respond to maintain system frequency. These are expensive and also have power gradient limitations. In principle, BESS with extremely high ramping capabilities may be explored for frequency regulation

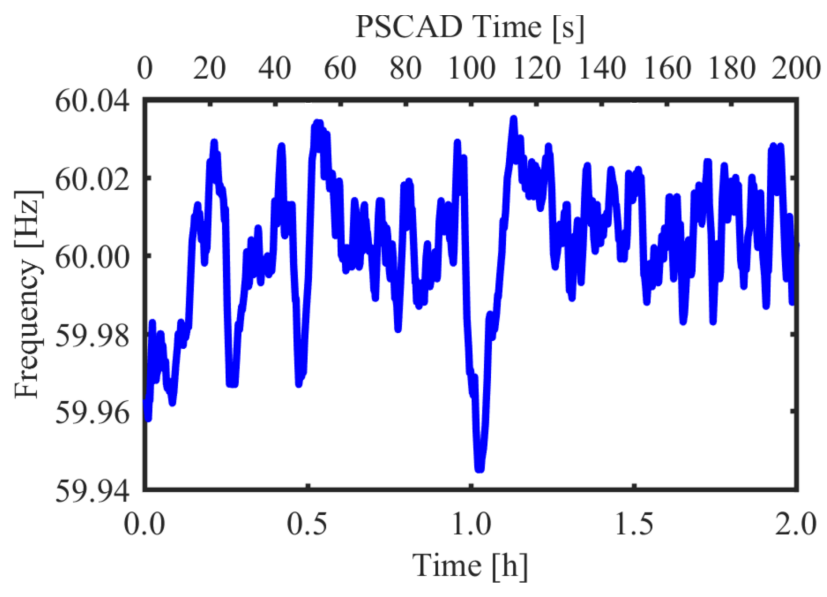

Figure 10. The experimental grid frequency variation. Imbalance between electric power generation and consumption typically leads frequency variation. Hence, utilities typically take measures to limit frequency variations by instantaneously meeting load demands.

by charging when the system frequency is above the desired value and discharging when it is low. It may be noted that this a function that requires the BESS to supply short bursts of power, and is therefore dependent on its power rating, rather than energy capacity.

In order to test and validate the developed BESS model and its controls under different operating conditions, its response to frequency variation was analyzed through a PSCAD - based study. The BESS was operated in its autonomous frequency mode, where it charges/discharges with respect to the observed frequency variation. For this study, a droop control based on Fig. 9 was adopted for both experimental and simulation setups, where $P_{r e f}^{*}$ was calculated as:

$P_{\text {ref }}^{*}(M W)=\Gamma * \begin{cases}-\frac{200}{9} \Delta f-0.1111, & 0.005 \leq|\Delta f| \leq 0.05 \\ 1, & |\Delta f| \geq 0.05 \\ 0, & \text { otherwise, }\end{cases}$

where, $\Delta f$ is 60 minus the actual frequency in $\mathrm{Hz}$ and $\Gamma$ is 1 when $\Delta f$ is positive and -1 if otherwise. PSCAD simulations as well as experiments were conducted with similar grid fre- 


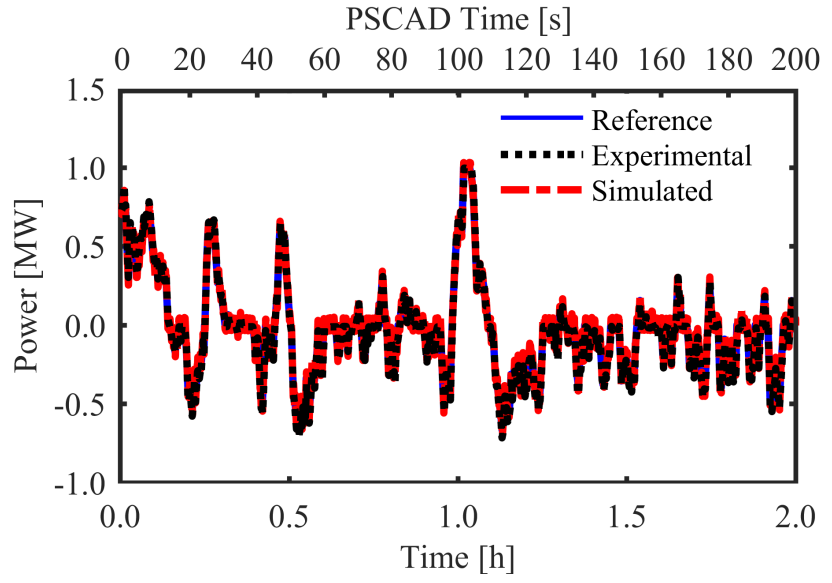

Figure 11. The BESS real power output. A reduction in grid frequency indicates insufficient electric generation, hence, the BESS supplies power to the grid to compensate for the deficit.

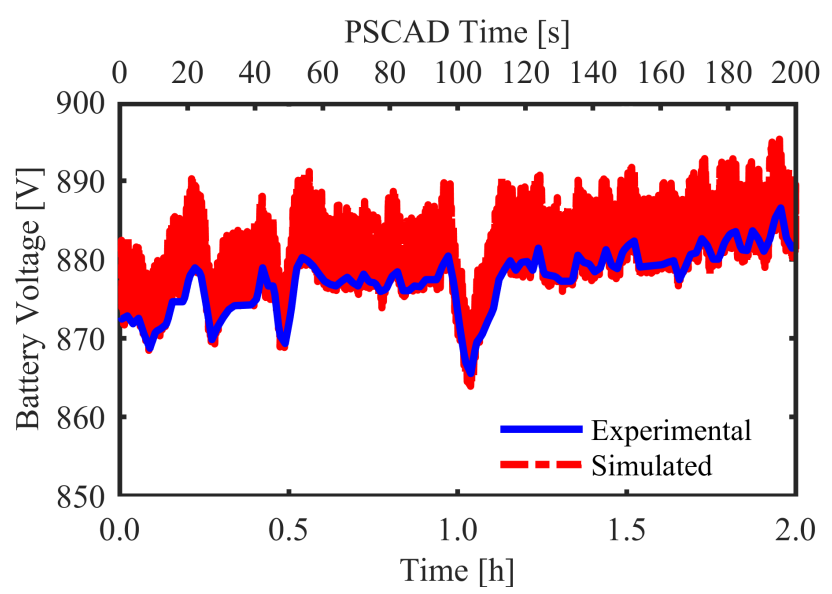

Figure 12. Battery terminal voltage during autonomous frequency response. High frequency variation is observed in the simulation battery voltage due to the switching of the power electronics devices, and a small sampling time.

quency variations as described in Fig. 10, and the output power and battery terminal voltage variations were compared. The simulated BESS output power closely follows the reference BESS real power calculated based on droop control, which demonstrates the efficacy of the control scheme. Furthermore, experimental measurements of real power output from the BESS are comparable with the simulation results (Fig. 11). The simulated battery terminal voltage variation under this operating mode also has close agreement with the measured value (Fig. 12). It may be noticed that the simulation results contain high switching frequency components, absent in the experimental results due to the smaller sampling frequency employed during measurement. The agreement between the simulation and experimental under different operating conditions results attests to the accuracy and versatility of the developed model.

\section{CONCLUSION}

This paper presents the modeling and simulation for a utility-scale battery energy storage system in PSCAD/EMTDC software. As opposed to conventional approaches, a robust equivalent circuit, whose parameters captures the dynamic behavior of all cells within the battery system as well as the variation with SOC was developed from experimental measurements on a $1 \mathrm{MW} / 2 \mathrm{MWh}$ battery housed at the LG\&E and KU E.W. Brown solar facility.

The propose runtime equivalent circuit offers multiple advantages, including reduced computational power for system designers to capture the dynamic response of all the cells within a battery and a platform for co-simulating the battery model developed in PSCAD/EMTDC with other compatible simulators. The accuracy of the developed model was verified from simulation and experimental measurements conducted under similar conditions. Both simulated and experimental battery systems were operated in autonomous grid frequency response mode, and the obtained battery output power and terminal voltage were found to be comparable. The results show that for the examples considered, up to $99 \%$ accuracy in the estimated battery voltage accuracy is achievable.

\section{ACKNOWLEDGMENT}

The support of University of Kentucky, the L. Stanley Pigman endowment, of the SPARK Laboratory, Power and Energy Institute of Kentucky (PEIK), and of LG\&E and KU is gratefully acknowledged.

\section{REFERENCES}

[1] F. Blaabjerg and D. M. Ionel, Renewable Energy Devices and Systems with Simulations in MATLAB® and ANSYS $\mathrm{B}$. CRC Press, Boca Raton, FL, 2017.

[2] A. Biswas, R. Gu, P. Kollmeyer, R. Ahmed, and A. Emadi, "Simultaneous state and parameter estimation of Li-ion battery with one state hysteresis model using augmented unscented kalman filter," in 2018 IEEE Transportation Electrification Conference and Expo (ITEC), June 2018, pp. 1065-1070.

[3] H. M. Usman, S. Mukhopadhyay, and H. Rehman, "Universal adaptive stabilizer based optimization for Li-ion battery model parameters estimation: An experimental study," IEEE Access, vol. 6, pp. 49546-49562, 2018.

[4] H. Chaoui, A. E. Mejdoubi, and H. Gualous, "Online parameter identification of lithium-ion batteries with surface temperature variations," IEEE Transactions on Vehicular Technology, vol. 66, no. 3, pp. 2000-2009, March 2017.

[5] V. Rallabandi, O. M. Akeyo, N. Jewell, and D. M. Ionel, "Incorporating battery energy storage systems into multi-MW grid connected PV systems," IEEE Transactions on Industry Applications, pp. 1-1, 2018.

[6] M. Farhadi and O. Mohammed, "Energy storage technologies for highpower applications," IEEE Transactions on Industry Applications, vol. 52 no. 3, pp. 1953-1961, May 2016.

[7] C. Gavriluta, J. I. Candela, J. Rocabert, A. Luna, and P. Rodriguez, "Adaptive droop for control of multiterminal dc bus integrating energy storage," IEEE Transactions on Power Delivery, vol. 30, no. 1, pp. 16-24 Feb 2015.

[8] A. S. Subburaj, S. B. Bayne, M. G. Giesselmann, and M. A. Harral, "Analysis of equivalent circuit of the utility-scale battery for wind integration," IEEE Transactions on Industry Applications, vol. 52, no. 1, pp. 25-33, Jan 2016 